\title{
Metabotropic Glutamate Receptor Subtype 7 in the Bed Nucleus of the Stria Terminalis is Essential for Intermale Aggression
}

\author{
Miwako Masugi-Tokita*,1,2,3, Peter J Flor ${ }^{4}$ and Mitsuhiro Kawata ${ }^{3,5}$ \\ 'World Premier Intemational Research Initiative-Institute for Integrated Cell-Material Sciences (WPI-iCeMS), Kyoto University, Kyoto, Japan; ${ }^{2}$ Institute for \\ Virus Research, Kyoto University, Kyoto, Japan; ${ }^{3}$ Department of Anatomy and Neurobiology, Kyoto Prefectural University of Medicine, Kyoto, Japan; \\ ${ }^{4}$ Faculty of Biology and Preclinical Medicine, University of Regensburg, Regensburg, Germany; ${ }^{5}$ School of Health Sciences, Bukkyo University, Kyoto, Japan
}

\begin{abstract}
Metabotropic glutamate receptor subtype 7 (mGluR7) is a member of group III mGluRs, which localize to the presynaptic active zones of the mammalian central nervous system. Although histological, genetic, and electrophysiological studies ensure the importance of mGluR7, its roles in behavior and physiology remain largely unknown. Using a resident-intruder paradigm, we found a severe reduction in intermale aggressive behavior in mGluR7 knockout (KO) mice. We also found alterations in other social behaviors in male mGluR7 KO mice, including sexual behavior toward male intruders. Because olfaction is critical for rodent social behavior, including aggression, we performed an olfaction test, finding that mGluR7 KO mice failed to show interest in the smell of male urine. To clarify the olfactory deficit, we then exposed mice to urine and analyzed c-Fos-immunoreactivity, discovering a remarkable reduction in neural activity in the bed nucleus of the stria terminalis (BNST) of mGluR7 KO mice. Finally, intra-BNST administration of the mGluR7-selective antagonist 6-(4-methoxyphenyl)5-methyl-3-pyridin-4-ylisoxazolo[4,5-c]pyridin-4(5H)-one (MMPIP) also reproduced the phenotype of mGluR7 KO mice, including reduced aggression and altered social interaction. Thus mGluR7 may work as an 'enhancer of neural activity' in the BNST and is important for intermale aggression. Our findings demonstrate that mGluR7 is essential for social behavior and innate behavior. Our study on mGluR7 in the BNST will shed light on future therapies for emotional disorders in humans.

Neuropsychopharmacology (2016) 4I, 726-735; doi:I0.I038/npp.20I5.198; published online 29 July 2015
\end{abstract}

\section{INTRODUCTION}

Glutamate receptors mediate most excitatory synaptic transmission in the mammalian central nervous system, and the metabotropic glutamate receptor (mGluR) family consists of eight G-protein-coupled receptors that modulate the activity of neural circuits (Hollmann and Heinemann, 1994; Nakanishi and Masu, 1994; Nicoletti et al, 2011). mGluRs are divided into three groups on the basis of signal transduction mechanisms and pharmacological properties. mGluR7 belongs to group III mGluRs, which localize presynaptically, close to neurotransmitter release sites (Okamoto et al, 1994). mGluR7 shows target cell-specific distribution that is differentially concentrated at particular axon terminals, depending on the nature of the postsynaptic neurons (Shigemoto et al, 1996). In many cases, single dendritic or somatic profiles are densely decorated by axon terminals with mGluR7 immunoreactivity (Shigemoto et al, 1996; Kinoshita et al, 1998). Interestingly, mGluR7

* Correspondence: Dr M Masugi-Tokita, World Premier International Research Initiative-Institute for Integrated Cell-Material Sciences (WPIiCeMS), Kyoto University, Kyoto 606-850I, Japan, Tel: +8I 75753 9844, Fax: +8I 75 75। 4807, E-mail: masugi.miwako.5u@kyoto-u.ac.jp Received 2 March 2015; revised 23 June 2015; accepted 29 June 2015; accepted article preview online 7 July 2015 internalization is critical for metaplasticity, and thus mGluR7 functions as a switch between long-term depression and long-term potentiation (Pelkey et al, 2005, 2008).

Although differential localization and electrophysiological properties suggest the importance of mGluR7 in neural circuits, the physiological relevance of this receptor remains to be fully elucidated. Previously, we reported that mGluR7 knockout (KO) mice showed a deficit in fear response and conditioned taste aversion, which are suggested to be regulated by the amygdala (Masugi et al, 1999). Based on our reports, many papers have discussed the link between mGluR7 and anxiety (Cryan et al, 2003; Mitsukawa et al, 2006; Fendt et al, 2008).

To assess a wider role for mGluR7 in emotional behavior, we focused on aggression. Aggression is fundamental for survival, and pheromonal signals have important roles in evoking intermale aggression (Leypold et al, 2002; Stowers et al, 2002; Nelson and Trainor, 2007). mGluR7 is widely distributed throughout the central nervous system, including vomeronasal circuits involving the accessory olfactory bulb (AOB), the medial amygdala (MeA), and the bed nucleus of the stria terminalis (BNST). In the BNST, some dendrites are decorated with mGluR7-expressing axon terminals (Kinoshita et al, 1998). The BNST is an extremely complex mass of gray matter (Ju and Swanson, 1989) that is 
composed of several subnuclei of varying reported numbers and locations (Alheid et al, 1995; Ju and Swanson, 1989; Moga et al, 1989; Franklin and Paxinos, 2007) and divided into anterior (BNSTa) and posterior (BNSTp) divisions. The BNSTa has started to receive increased attention since it was discovered that it regulates anxiety (Kim et al, 2013) and motivational states (Jennings et al, 2013a, b), but the cytoarchitecture and function of the BNSTp are still poorly understood. In the present study, we focused on the role of mGluR7 in the BNSTp regulating social behaviors, as exemplified by intermale aggression.

\section{MATERIALS AND METHODS}

See also Supplementary Information online.

\section{Animals}

Sexually inexperienced, gonadally intact male mice (1224 weeks old) were used. mGluR7 KO and wild-type littermates were obtained from heterozygous mating couples, which were produced by back-crossing the mGluR7 KO line lacking the first coding exon and next intron of the mGluR7 gene (Masugi et al, 1999; Sansig et al, 2001; Cryan et al, 2003) into the $\mathrm{C} 57 \mathrm{BL} / 6 \mathrm{~N}$ background for at least 11 generations. For microinjection experiments, C57BL/6N male mice were originally purchased from a commercial breeder (SHIMIZU Laboratory Supplies, Kyoto, Japan). All animal protocols were compliant with the National Institutes of Health Guide for the Care and Use of Laboratory Animals and were approved by the Committee for Animal Research, Kyoto Prefectural University of Medicine, and Kyoto University.

\section{Aggressive Behavior and Social Behavior (Resident-Intruder Test)}

Mice ( $n=10$ for each genotypes) were tested for aggressive behaviors six times (once a week) in the resident-intruder paradigm (Ogawa et al, 1998). Each male was tested in his home cage (as a resident) against a group-housed (3-5 mice per cage) olfactory bulbectomized male ICR intruder mouse (Denenberg et al, 1973; Ogawa et al, 1996) for $15 \mathrm{~min}$. Cumulative duration of all aggressive bouts, and latency to the first aggressive act were all recorded. We defined aggressive behaviors into three distinct categories in the following way:

1. Intense aggression: Biting, boxing, wrestling, tumbling.

2. Mild aggression: Chasing, attempted mount, mount.

3. Sexual behavior: Mount with vigorously palpating the flanks of the intruder, just like trying to induce lordosis of female mice.

We also recorded several social investigating behaviors simultaneously:

4. Anogenital sniffing: Nose-to-anogenital area investigation.

5. Sniff other areas: Nose-to-whole body investigation other than anogenital area.

6. Grooming the intruder.

\section{Urine Preference Test (Olfaction Test)}

Singly housed and sexually inexperienced wild-type $(n=21)$ and mGluR7 KO males $(n=21)$ not previously tested for aggression were used to determine whether they exhibited a preference for male or hormone-primed female urine or saline (Mandiyan et al, 2005). A fresh absorbent cotton pad, handled only with gloves, was wetted with $40 \mu \mathrm{l}$ of male urine, female urine, or saline. Two cotton pads wetted with different odorant sources were presented simultaneously to the mice at random locations in the home cage for $10 \mathrm{~min}$. The duration of sniffing was recorded.

\section{Urine Exposure for c-Fos Induction}

Individually housed and sexually inexperienced male mGluR7 KO mice and their littermates not previously tested for aggression were used for c-Fos induction. Mice were trained daily, for 2 weeks, in the manipulation used for urine exposure. During the dark phase of the light/dark cycle, animals were taken out of their home cage and received $10 \mu \mathrm{l} \times 3$ of saline onto their nose and then placed back into their cage. On the day of urine exposure, they were divided into three groups depending on the odor stimulus that they were going to be exposed to. Group $1 \quad(n=6$ for each genotypes) was exposed to intact male urine, group 2 ( $n=5$ for each genotypes) to hormone-primed female urine, and group 3 ( $n=6$ for each genotypes) to saline as control.

Ninety minutes later, mice were anesthetized with sodium pentobarbital and subjected to transcardiac perfusion with formaldehyde (4\%; freshly depolymerized from paraformaldehyde) in $0.1 \mathrm{M}$ sodium phosphate buffer. After perfusion, the brains were removed, and postfixed in the same fixative for $12 \mathrm{~h}$. Brains were then cryoprotected in 30\% sucrose/ $0.1 \mathrm{M}$ sodium phosphate buffer and quickly frozen with liquid carbon dioxide and cut into $40-\mu \mathrm{m}$ serial coronal sections using a cryostat (CM3050 S; Leica Microsystems, Wetzlar, Germany).

\section{Pharmacological Treatment and Site-Directed Injections}

For the BNST and MeA, $0.25 \mu \mathrm{l}(5 \mu \mathrm{g} / \mu \mathrm{l})$ of MMPIP (MMPIP250) dissolved in a solution of dimethyl sulfoxide (DMSO) or DMSO (DMSO250) as a control was infused. For lateral ventricle injection, $0.25 \mu \mathrm{l}$ or $0.75 \mu \mathrm{l}$ of MMPIP (MMPIP750) or $0.75 \mu$ l of DMSO (DMSO750) was infused. Testing began $60 \mathrm{~min}$ after infusion. Within each group, a within-subjects repeated-measures design was used.

\section{Statistics}

Behavioral data were analyzed by a two-way ANOVA for repeated measurements or unpaired $t$-test for independent samples or paired $t$-test for matched samples. Some behavioral data (in which variances were not homogeneous between genotype groups) were analyzed by nonparametric tests (Mann-Whitney $U$-test for independent samples or Wilcoxon matched pairs signed ranks test for matched samples).

\section{RESULTS}

\section{Impaired Intermale Aggression in mGluR7 KO Mice}

Using the resident-intruder paradigm, we performed six once-a week tests of the aggressive behavior of mGluR7 KO 

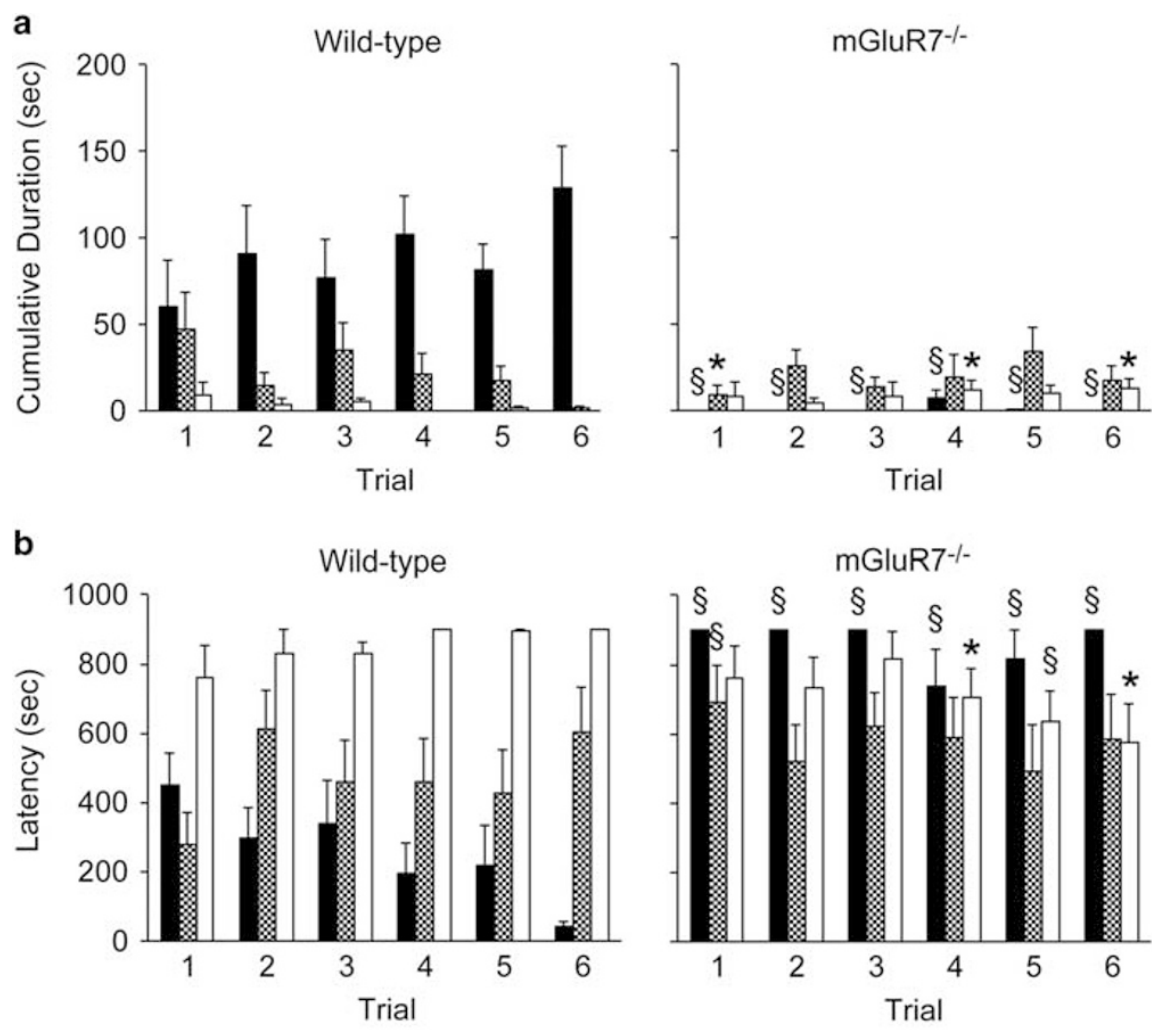

Intense aggression $\approx$ Mild aggression $\square$ Sexual behavior

Figure I Impaired aggression in male mGluR7 KO mice toward male intruders. Cumulative duration (a) and latency (b) of aggressive behavior, as measured by the resident-intruder paradigm. Male wild-type mice showed intense aggressions, which increased with experience, whereas male $\mathrm{mGluR7} \mathrm{KO}$ mice rarely showed intense aggressive behavior throughout the test. Male mGluR7 KO mice more frequently showed sexual behavior toward male intruders than their wild-type littermates. $n=10$. $* P<0.05$ vs wild-types, $\S P<0.01$ vs wild-types in each individual trial. Error bars indicate SEM.

male resident mice toward an olfactory bulbectomized male intruder mouse. Because olfaction is important for aggression, olfactory bulbectomized intruders rarely show aggression. However, because their gonads are intact, they can elicit aggression in resident male mice (Ogawa et al, 1998). All tested mice were singly housed to induce territorial aggression through our study. Although this is one of the standard protocols, we should be aware that social isolation affects behavioral, physiological, and biochemical parameters (Miczek et al, 2001). We found that the mean duration of intense aggressive behavior (biting, boxing, wrestling, and tumbling; main effect of genotype, $\mathrm{F}_{(1,18)}=28.3, P<0.001$; main effect of trial, $\mathrm{F}_{(5,18)}=1.8, P=0.12$; genotype $\times$ trial interaction, $F_{(5,18)}=1.6, P=0.17$, Figure 1a) and the mean latency to the first intense aggressive act (main effect of genotype, $\mathrm{F}_{(1,18)}=54.4, \quad P<0.001$; main effect of trial, $\mathrm{F}_{(5,18)}=4.6, \quad P<0.001 ; \quad$ genotype $\times$ trial interaction, $\mathrm{F}_{(5,18)}=3.0, P=0.016$; Figure $\left.1 \mathrm{~b}\right)$ of the mGluR7 KO mice were different from those of their wild-type littermates, as assessed by repeated-measures ANOVA. The mean duration and latency were different in all six trials, as assessed by unpaired $t$-test or Mann-Whitney $U$-test $(P<0.01$, Figure 1$)$. In the wild-type controls, the intense aggression gradually increased with fighting experience, as previously reported (Lagerspetz and Lagerspetz, 1971), whereas mGluR7 KO mice showed almost no intense aggression, even in the sixth trial. These results show that mGluR7 KO mice have a severe deficit in aggression.
Chasing, attempted mount, and mount are ways of showing dominance between males but are also observed in male-tofemale sexual behavior. We defined these behaviors as mild aggression. Both groups showed almost equivalent levels of the mean duration of mild aggression (main effect of genotype, $\mathrm{F}_{(1,18)}=0.1, P=0.73$; main effect of trial, $\mathrm{F}_{(5,18)}=0.8, P=0.54$; genotype $\times$ trial interaction, $F_{(5,18)}=2.4, P=0.046$; Figure 1a) and the mean latency to the first mild aggressive behavior (main effect of genotype, $\mathrm{F}_{(1,18)}=1.5, P=0.24$; main effect of trial, $\mathrm{F}_{(5,18)}=0.4, P=0.82$; genotype $\times$ trial interaction, $\mathrm{F}_{(5,18)}=1.3, P=0.27$; Figure 1b). Only in the first trial, the mean duration and latency of mild aggression of mGluR7 KO mice were different from those of wild-type mice $(z=-2.2$, $P=0.030$, Mann-Whitney $U$-test; $t_{(18)}=2.9, P=0.0095$, unpaired $t$-test; respectively; Figure 1). These results suggest that mGluR7 KO mice have normal level of motivation to interact with the intruder and that impaired intense aggression in mGluR7 KO mice is not due to reduced motivation of social interaction.

Interestingly, mGluR7 KO mice showed sexual behaviors (mount and vigorously palpating the flanks of the intruder) toward male intruders, behaviors that are normally used to induce lordosis in female mice. Sexual behaviors toward male intruders was also seen in 2 out of 10 wild-type mice at the beginning of the trials, but no wild-type mouse showed sexual behavior in the fourth and sixth trials. Repeatedmeasures ANOVA revealed that there was statistical significance between the two groups in the mean latency to 
the first sexual behavior (main effect of genotype, $\mathrm{F}_{(1,18)}=9.9, \quad P=0.006$; main effect of trial, $\mathrm{F}_{(5,18)}=0.4$, $P=0.87$; genotype $\times$ trial interaction, $\mathrm{F}_{(5,18)}=1.7, P=0.15$; Figure $1 \mathrm{~b})$, but no significance in the mean duration of first sexual behavior (main effect of genotype, $F_{(1,18)}=3.9$, $P=0.064$; main effect of trial, $\mathrm{F}_{(5,18)}=0.2, P=0.96$; genotype $\times$ trial interaction, $F_{(5,18)}=0.7, P=0.62 ;$ Figure 1a). However, there were considerable differences in the mean duration of sexual behavior in the fourth and sixth trials, $(z=-1.5, P=0.031 ; z=-1.9, P=0.013$; respectively; MannWhitney $U$-test; Figure 1a) and in the mean latency to the first sexual behavior in the fourth to sixth trials $(z=-1.5$, $P=0.031$, Mann-Whitney $U$-test; $t_{(18)}=-2.9, \quad P=0.0098$, unpaired $t$-test; $z=-1.9, P=0.013$, Mann-Whitney $U$-test; respectively; Figure 1b).

\section{Altered Social Investigation in mGluR7 KO Mice}

Social recognition in mice is primarily based on olfaction. Urinary pheromones and their binding proteins have important roles in the individual recognition mechanism (Hurst et al, 2001). During social encounters, a male mouse investigates a novel mouse by sniffing the anogenital region, as well as the rest of the body, including nose-to-nose sniffing. Here we further analyzed the social investigating behavior. Wild-type mice reacted quickly toward intruder mice by investigating the anogenital region, followed by a bite or fighting. Interestingly, mGluR7 KO mice showed a marked reduction in the duration of anogenital sniffing (main effect of genotype, $\mathrm{F}_{(1,18)}=17.2, P<0.001$; main effect of trial, $\mathrm{F}_{(5,18)}=6.8, P<0.001$; genotype $\times$ trial interaction, $\mathrm{F}_{(5,18)}=4.6, P<0.001$; Figure $2 \mathrm{a}$ ) and took a longer time to initiate the first anogenital sniffing (main effect of genotype, $\mathrm{F}_{(1,18)}=33.8, \quad P<0.001$; main effect of trial, $\mathrm{F}_{(5,18)}=1.2$, $P=0.31$; genotype $\times$ trial interaction, $\mathrm{F}_{(5,18)}=1.2, P=0.30$; Figure $2 \mathrm{~b})$, as assessed by repeated-measures ANOVA.

In contrast, a slight increase was observed in the time spent sniffing the other parts of the body. mGluR7 KO mice sniffed the intruder more than their wild-type littermates (main effect of genotype, $\mathrm{F}_{(1,18)}=14.2, P=0.0014$; main effect of trial, $\mathrm{F}_{(5,18)}=5.3, P<0.001$; genotype $\times$ trial interaction, $\mathrm{F}_{(5,18)}=1.3, P=0.29$; Figure $\left.2 \mathrm{a}\right)$ and quicker than wild types (main effect of genotype, $\mathrm{F}_{(1,18)}=16.3, P<0.001$; main effect of trial, $\mathrm{F}_{(5,18)}=1.2, P=0.30$; genotype $\times$ trial interaction, $\mathrm{F}_{(5,18)}=1.3, P=0.29$; Figure $\left.2 \mathrm{~b}\right)$, as assessed by repeatedmeasures ANOVA. These results suggest that reduced duration of anogenital sniffing in mGluR7 KO mice is not due to a reduced interest in investigating the intruder.

mGluR7 KO mice showed grooming behaviors toward the intruder. The mean duration of intruder grooming (main effect of genotype, $\mathrm{F}_{(1,18)}=18.7, P<0.001$; main effect of trial, $\mathrm{F}_{(5,18)}=1.0, \quad P=0.41 ;$ genotype $\times$ trial interaction, $\mathrm{F}_{(5,18)}=1.2, P=0.34$; Figure $\left.2 \mathrm{a}\right)$ and the mean latency to the first grooming (main effect of genotype, $\mathrm{F}_{(1,18)}=20.4$, $P<0.001$; main effect of trial, $\mathrm{F}_{(5,18)}=0.8, P=0.50$; genotype $\times$ trial interaction, $\mathrm{F}_{(5,18)}=1.9, P=0.11$; Figure $2 \mathrm{~b}$ ) were different between wild-type and mGluR7 KO mice.

\section{Altered Urine Preference in mGluR7 KO Mice}

Because we found reduced duration of anogenital sniffing in mGluR7 KO mice and because urine pheromones are important for eliciting sexual and aggressive behaviors (Leypold et al, 2002; Stowers et al, 2002; Chamero et al, 2007), we next examined urine preference. Mice were exposed to two absorbent cotton pads wetted with male or hormone-primed female urine for $10 \mathrm{~min}$. As expected, wildtype males showed a preference for female urine $\left(t_{(7)}=7.4\right.$, $P<0.0001$, paired $t$-test; Figure 3a). mGluR7 KO mice also had a preference for female urine $\left(t_{(7)}=2.8, P=0.025\right.$, paired $t$-test), but the cumulative duration that they spent sniffing the female urine was significantly shorter than that of wildtype mice $\left(t_{(14)}=-3.7, P=0.0026\right.$, unpaired $t$-test).

We next presented male urine and saline simultaneously. Wild-type mice spent significantly more time investigating the male urine than the saline $\left(t_{(12)}=-4.5, P=0.008\right.$, paired $t$-test; Figure $3 \mathrm{~b})$. In contrast, mGluR7 $\mathrm{KO}$ mice failed to sniff either cotton pad preferentially $\left(t_{(12)}=1.0, P=0.32\right.$, paired $t$-test). Furthermore, the duration that wild-type mice sniffed the male urine was longer than that of mGluR7 KO mice sniffed the male urine or saline $(z=-3.7, P=0.0002$; $z=-2.1, \quad P=0.032$; respectively; Mann-Whitney $U$-test). Using a habituation-dishabituation test, we found that mGluR7 KO mice can discriminate urine odors and that they can respond to novel stimulus (Supplementary Figure $\mathrm{S} 1$ ). Thus these results show that mGluR7 KO mice have altered urine preference.

\section{Reduced c-Fos Induction after Urine Exposure in the BNSTp of mGluR7 KO Mice}

The response to urine pheromones, which is important for social recognition and initiation of aggressive behaviors, begins with pheromone detection in the vomeronasal organ (Chamero et al, 2007), and the information is then conveyed to the AOB. The AOB directly projects to the MeA, which itself projects to the BNST; the BNST also receives direct projections from the AOB (Yoon et al, 2005). Figure 4a schematically illustrates the flow of pheromonal information in the rodent. Altered urine preference and aggressive behavior of mGluR7 KO mice may be a consequence of mGluR7 dysfunction in this circuitry. To identify the candidate sites for the processing of olfactory cues, we compared the neural activation patterns in mGluR7 $\mathrm{KO}$ and wild-type mice after urine exposure using the protein product of the immediate early gene $c$-fos.

Because there were differences in the duration of olfactory investigation, we directly applied urine or saline to the nose of mice. After $90 \mathrm{~min}$ of urine exposure, mice were killed and immunohistochemistry for c-Fos was performed. We compared various brain regions between wild-type and mGluR7 KO mice exposed to male urine, hormone-primed female urine, or saline.

First, we examined the $\mathrm{AOB}$, the first relay station of the pheromonal information. The analysis of the c-Fos-immunoreactivity (ir) of various brain regions is shown in Supplementary Figure S2. The c-Fos responses for male and female urine were very similar between wild-type and mGluR7 KO mice in both the mitral cell layer $\left(t_{(10)}=0.1\right.$, $P=0.92 ; t_{(8)}=0.6, P=0.58 ;$ respectively; unpaired $t$-test; Figure $4 \mathrm{~b}$, left panel, and Supplementary Figure S2) and the granule cell layer $\left(t_{(10)}=0.8, P=0.46 ; t_{(8)}=-1.2\right.$, $P=0.28$; respectively; unpaired $t$-test; Figure $4 \mathrm{~b}$, right panel, and Supplementary Figure S2). 

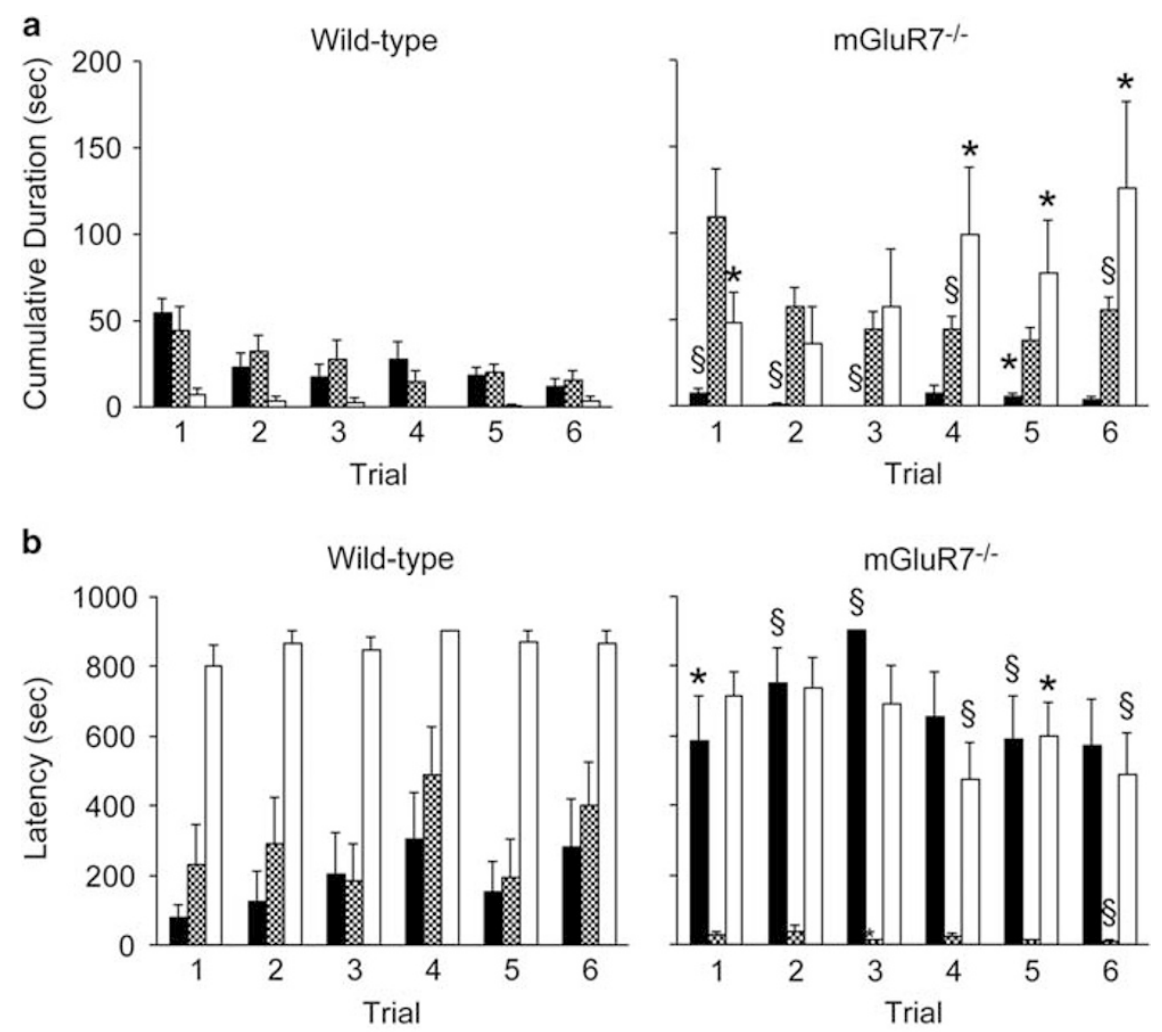

- Anogenital sniffing $\mathbb{\otimes}$ Sniff other areas $\square$ Grooming partner

Figure 2 Altered social investigating behavior in male mGluR7 KO mice. Cumulative duration (a) and latency (b) of social behavior as measured by the resident-intruder paradigm. Duration of anogenital sniffing of intruder mice was reduced in mGluR7 KO mice. Note that mGluR7 KO mice frequently showed grooming behavior that was rarely seen in wild-type mice. $n=10$, *P $<0.05$ vs wild types, $\$ P<0.01$ vs wild types on each individual trial. Error bars indicate SEM.

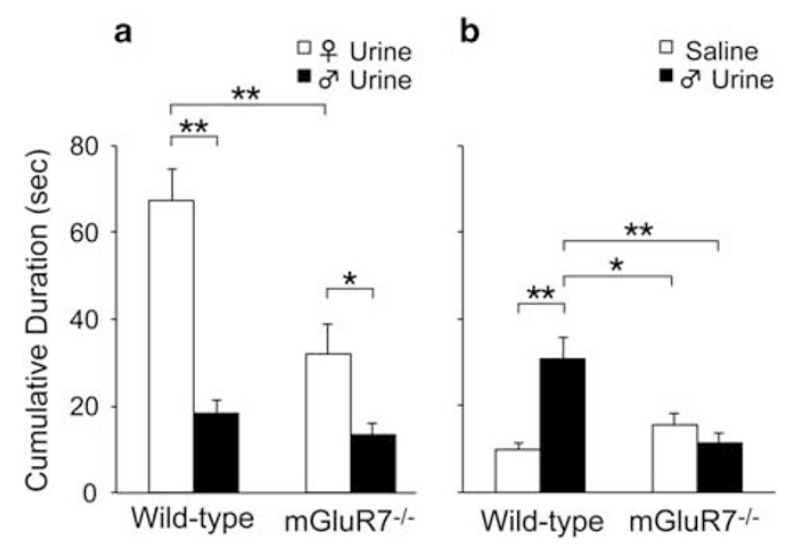

Figure 3 Altered urine preference in male mGluR7 KO mice. (a) Wildtype mice sniffed female urine for a longer duration than their mGluR7 KO littermates. (b) Wild-type mice spent significantly longer duration of sniffing male urine than sniffing saline; no such preference was observed in mGluR7 KO mice. $n=8$ for (a), $n=13$ for (b). $* P<0.05$, **P<0.01. Error bars indicate SEM. See also Supplementary Figure SI.

Next we examined c-Fos expression in secondary vomeronasal centers, namely, the posterior region of the MeA. Again, c-Fos responses for male and female urine were similar between wild-type and mGluR7 KO mice in both the posterodorsal MeA (MePD; $t_{(10)}=0.7, P=0.52 ; t_{(8)}=-0.3$, $P=0.81$; respectively; unpaired $t$-test; Figure $4 \mathrm{c}$, left panel, and Supplementary Figure S2) and posteroventral MeA $\left(\mathrm{MePV} ; t_{(10)}=1.2, P=0.28 ; t_{(8)}=-0.2, P=0.87\right.$; respectively; unpaired $t$-test; Figure $4 \mathrm{c}$, right panel, and Supplementary Figure S2). Importantly, these results suggest that pheromonal information in mGluR7 $\mathrm{KO}$ mice is normal until it reaches the MeA.

Finally, we examined the BNSTp, which is connected to the MeA and AOB (Figure 4a). The c-Fos-ir in the BNSTp induced by exposure to both male and female urine in mGluR7 KO mice was reduced compared with wild types $\left(t_{(10)}=-3.1, P=0.011 ; t_{(8)}=-10.1, P=0.0001\right.$; respectively; unpaired $t$-test; Figure $4 \mathrm{~d}-\mathrm{f}$ ). These results indicate that mGluR7 KO mice have a deficit in processing pheromonal information within the BNSTp.

\section{Reproduction of the mGluR7 KO Phenotype by Intra- BNSTp Injection of the mGluR7-Selective Antagonist MMPIP}

The reduced c-Fos induction in the BNSTp of mGluR7 KO mice strongly suggested that mGluR7-mediated olfactory processing in this brain region is essential for intermale aggression. To complete the links between impaired aggression and reduced c-Fos-ir after urine exposure and to specify the site of action of mGluR7, we performed the residentintruder test after intracerebral microinjection of the mGluR7-selective antagonist MMPIP. The BNSTp has strong connections with the MePD and MePV (Dong and Swanson, 2004; Bienkowski et al, 2013). The area of reduced c-Fos-ir 

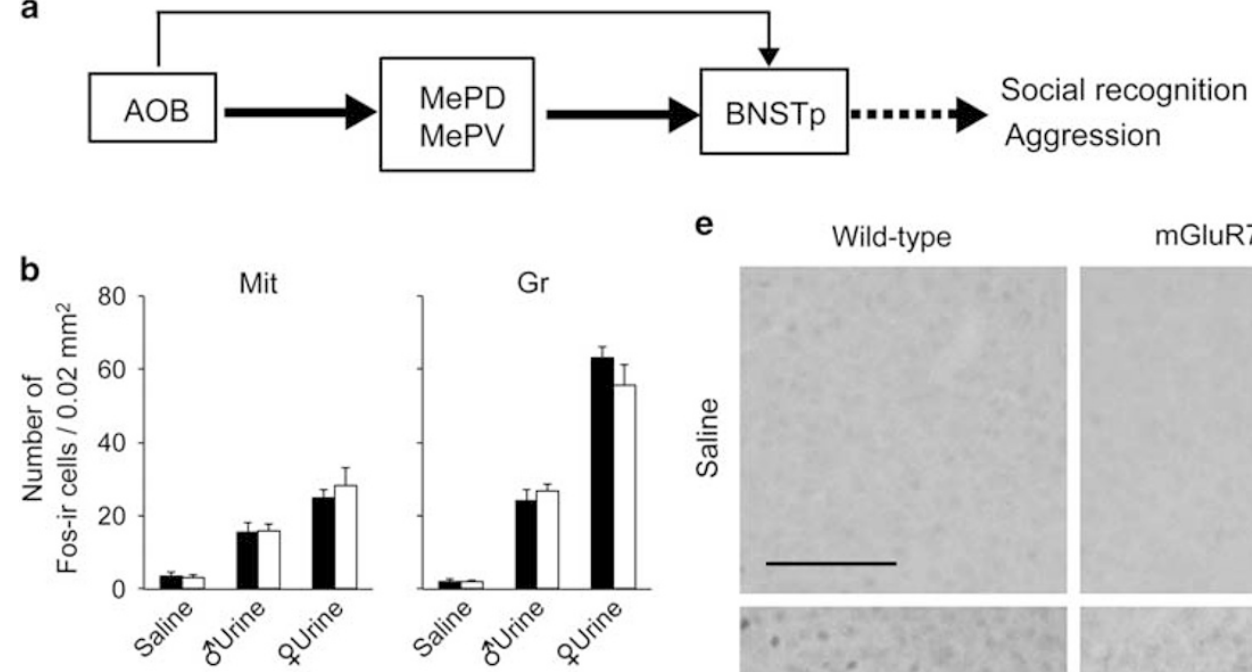

e

C

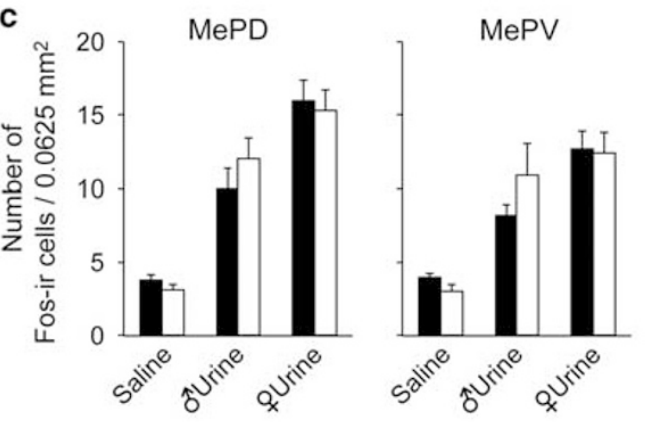

- Wild-type

a mGluR7-l-
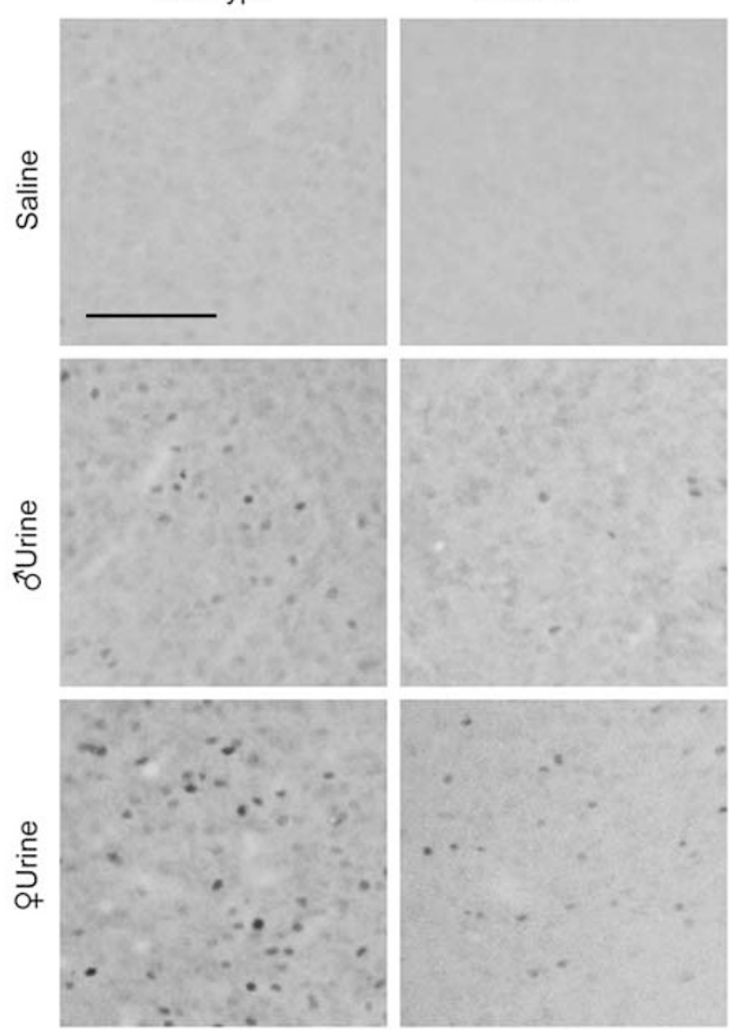

d

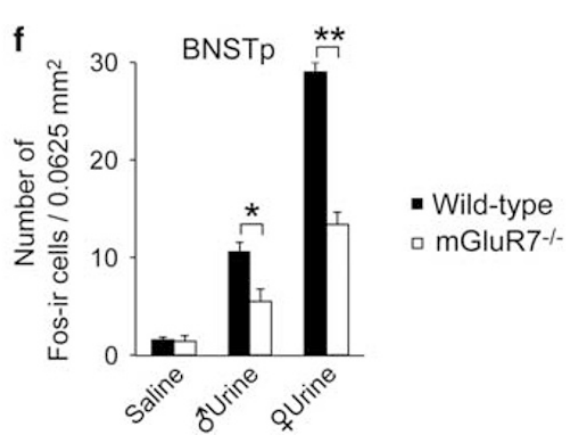

Figure 4 Reduced c-Fos activation in the BNSTp of mGluR7 KO mice. (a) Schematic illustration of the flow of pheromonal information in the rodent brain. (b-f) Quantification of c-Fos-expressing cells in each region. In both genotypes, exposure to urine increased c-Fos-ir in the mitral cell layer (Mit) and granule cell layer $(\mathrm{Gr})$ of the accessory olfactory bulb (AOB), the posterodorsal (MePD) and posteroventral medial amygdala (MePV), and posterior division of the bed nucleus of the stria terminalis (BNSTp), and the response to female urine was greater than that to male urine. (d) Representative microscopic images of c-Fosir in the BNSTp of male wild-type mice after male urine exposure. The boxes approximate the regions analyzed. (e, f) Representative microscopic images and quantification of c-Fos-ir in the BNSTp of male wild-type and mGluR7 KO mice after saline, male urine, and female urine exposure. The scale bars indicate $100 \mu \mathrm{m}$. Note that a remarkable reduction in c-Fos-ir after urine exposure was seen in the BNSTp of mGluR7 KO mice. $* P<0.05$, $* * P<0.0$ I. Error bars indicate SEM. See also Supplementary Figure S2.

and the anatomical relationships strongly suggest that this area is the prime candidate for the action in our study; we therefore injected MMPIP into the BNSTp. Because the surgery itself increased the latency to the first aggressive behavior of most mice and to avoid repeated microinjections, we trained the mice until the latency to the first incident of intense aggression became $<180 \mathrm{~s}$ before testing the effect of
MMPIP in our aggressive behavior tests. The mice used in the microinjection study are summarized in Supplementary Table S1.

Intra-BNSTp microinjection of MMPIP significantly reduced the durations of intense aggressive behavior $\left(t_{(9)}=4.1, P=0.0015\right.$, paired $t$-test; Figure $5 \mathrm{a}$, left panel) and anogenital sniffing $\left(t_{(9)}=4.6, P=0.0045\right.$, paired $t$-test; 

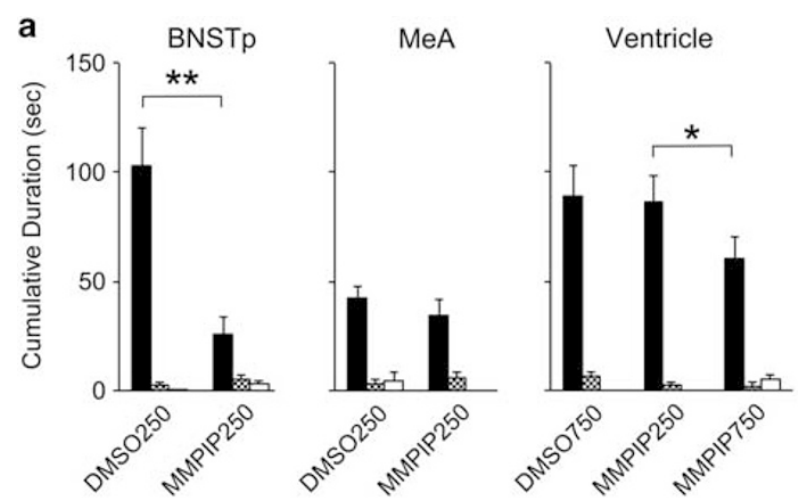

- Intense aggression $\otimes$ Mild aggression $\square$ Sexual behavior

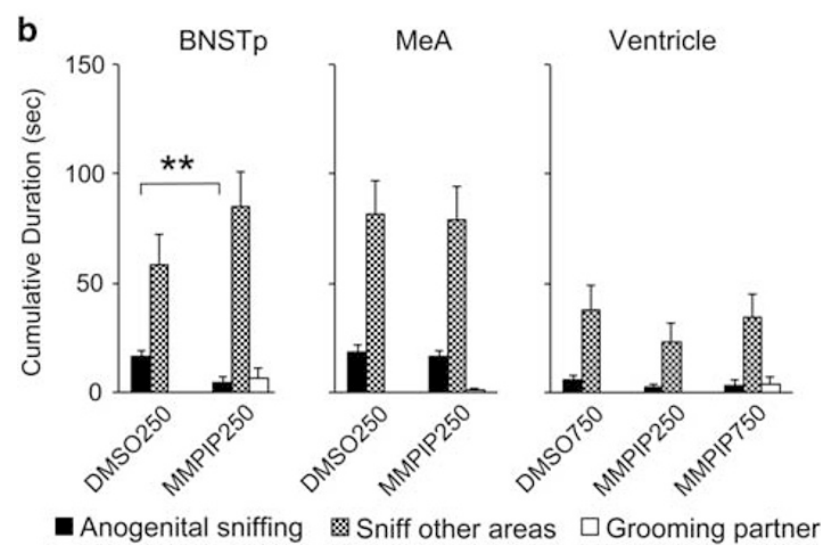

Figure 5 Effects of MMPIP injection on aggressive behavior and social investigation in wild-type male mice. Cumulative duration of aggressive behavior (a) and social behavior (b), as measured by the resident-intruder paradigm. Intra-posterior division of the bed nucleus of the stria terminalis (BNSTP) injections of MMPIP reduced aggression, whereas intra-medial amygdaloid (MeA) injections had no effect. Intra-lateral ventricle injections needed a higher dose of MMPIP to induce behavioral alterations, indicating that the effect of intra-BNSTp injection was not due to diffusion into the lateral ventricle. $n=10$ for the BNSTp, $n=7$ for the MeA, $n=5$ for the lateral ventricle; $* P<0.05$, $* * P<0.01$. Error bars indicate SEM. See also Supplementary Table SI.

Figure 5b, left panel). Moreover, 2 out of 10 MMPIP-injected mice showed sexual behavior toward male intruders, and 3 showed grooming behavior, whereas vehicle-injected mice did not show such behaviors (statistical assessment not possible due to low animal numbers). These results indicate that MMPIP infusion into the BNSTp induced very similar effects to mGluR7 deficiency in the resident-intruder test. Intra-MeA injection of MMPIP had no effect on any of the parameters measured (Figure $5 \mathrm{a}$ and $\mathrm{b}$, middle panels).

Although the injections were clearly within the BNSTp or $\mathrm{MeA}$, we cannot exclude the possibility that diffusion into adjacent regions impacted the behavior. To rule out such a possibility, we injected MMPIP into the lateral ventricle, because the BNSTp is located very close to the lateral ventricle and MMPIP might diffuse into the ventricle. Intralateral ventricle microinjection of the same amount of MMPIP that reduced the aggression in the BNSTp had no effect on any of the parameters measured. Then we administered triple the amount of MMPIP into the lateral ventricle; although there was no statistical significance in the duration of intense aggression between MMPIP750 and the vehicle control, DMSO750 $\left(t_{(4)}=1.4, P=0.25\right.$, paired $t$-test; Figure 5a, right panel), slight reduction was observed in MMPIP750 compared with MMPIP250 injection $\left(t_{(4)}=-4.0\right.$, $P=0.016$, paired $t$-test). These results suggest that the effects of MMPIP infusion into the BNSTp are not due to diffusion into the lateral ventricle and that an excess dose of MMPIP into the lateral ventricle may affect adjacent areas, including the BNSTp. Taken together, these results indicate that mGluR7 located in the BNSTp has important roles in controlling intermale aggression.

\section{DISCUSSION}

The present analysis of mGluR7 KO mice, c-Fos expression, and cerebral MMPIP microinjection indicate that inhibition of mGluR7 impairs intermale aggression owing to information processing dysfunction within the BNST. It is well known that the vomeronasal system is critical for social recognition; therefore, congenital loss of vomeronasal function reduces male-to-male aggression and male-tofemale sexual behavior but increases male-to-male sexual behavior (Leypold et al, 2002; Stowers et al, 2002; Chamero et al, 2007), while the main olfactory system also has an involvement (Mandiyan et al, 2005). Male-to-male sexual behavior, reduced duration of anogenital sniffing, and altered urine preference are all consistent with impaired pheromonal information processing, indicating that male mGluR7 KO mice show severe loss of social recognition to other males. The c-Fos-ir pattern in the mGluR7 KO mice indicates that pheromonal information in these mice is detected by the vomeronasal organ and processed normally until it reaches the MeA, but the BNST cannot respond properly. Thus mGluR7 has a crucial role in excitation of the BNST neurons to manage social perception.

Although mGluR7 has been postulated to be one of the most important mGluRs, the physiological roles of mGluR7 in the brain are mostly unclear because of lacking pharmacological tools until recently. MMPIP is a negative allosteric modulator that possesses high subtype selectivity (Conn et al, 2009). Here microinjection of MMPIP into the BNST clearly reproduced the mGluR7 KO phenotype in all parameters tested. Importantly, our microinjection study also showed that the impaired aggression of mGluR7 KO mice cannot be attributed to deficits in the formation of neural circuits without mGluR7 during neural development but that modulation of synapses by mGluR7 is necessary for evoking aggression.

\section{The Role of the BNST in Regulating Emotional Behavior}

The BNSTa is currently receiving increased attention, because this area regulates several emotional and motivational processing and because some components of the important pathways in the BNSTa have been revealed, despite the complex circuits involved (Kim et al, 2013; Jennings et al, 2013a, b). The most obvious cell groups in the BNSTp include the principal, interfascicular, and transverse nuclei (Ju and Swanson, 1989). The principal nucleus has crucial roles in controlling the neuroendocrine system and reproductive behavior (Choi et al, 2007; Simerly, 2002), but little is known about the interfascicular and transverse nuclei. 
Only fragmentary and controversial evidence suggests their involvement in defensive behaviors (Shaikh et al, 1986; Patil and Brid, 2010). Through our study, we noticed that cannulation or microinjection into the BNSTp affects mice aggression, some mice never show aggression, and some mice became hyperaggressive (Supplementary Table S1). These observations indicate the heterogeneous functions of the BNST and explain why previous lesion studies of the BNST have been controversial (Shaikh et al, 1986; Patil and Brid, 2010).

Although the BNST is composed of mainly $\gamma$-aminobutyric acid (GABA)-releasing cells, glutamatergic neurons are more common in the BNSTp than in the BNSTa (Poulin et al, 2009; Kudo et al, 2012). Blockade of AMPA receptor activity within the BNST is reported to reduce aggression (Carrillo et al, 2011), suggesting that the glutamatergic system in the BNST facilitates aggression. It is likely that mGluR7 modulates the synaptic efficacy of these glutamatergic terminals, although it is unknown if the circuits are extrinsic or intrinsic.

Serotonin has long been considered as a key transmitter in the neurocircuitry controlling aggression (Ferris et al, 1997; Miczek et al, 2001; Nelson and Trainor, 2007). Low-dose cocaine treatment during adolescence facilitates aggression and induces marked decrease in serotonergic innervations in several aggression areas, including the BNST (DeLeon et al, 2002). As excitation of the BNSTp correlate with aggression, the serotonergic signaling in this brain region may function to inhibit the activity of neurons critical to elicit aggression. Because mGluR7 deficiency reduced the urine-induced neural activity in the BNSTp, it is plausible to speculate a functional interaction between mGluR7 and the serotonergic system. The neuropeptides arginine vasopressin (AVP) and oxytocin are important modulators of several social behaviors (Veenema and Neumann, 2008). In addition to paraventricular and supraoptic nuclei, the BNST also contains AVP-synthesizing neurons (De Vries and Buijs, 1983). There is compelling evidence that AVP is important for social recognition (Caldwell et al, 2008), and the expression level of the oxytocin receptor in the BNST is associated with aggression (Calcagnoli et al, 2014). Furthermore, the relationship between AVP and the serotonergic system in the regulation of aggressive behavior has been demonstrated in several studies (Ferris et al, 1997; D'Eath et al, 2005). Because mGluR7 is expressed on both glutamatergic and GABAergic terminals (Kinoshita et al, 1998; Somogyi et al, 2003), mGluR7 may also regulate the release of serotonin, AVP, oxytocin, or GABA, directly or indirectly.

The BNSTp contains many kinds of neurotransmitters (Moga et al, 1989), which should be examined in a future study. Although the complexity of the intrinsic and extrinsic circuits hampered elucidation of the mechanism, we clearly showed that mGluR7 in the BNST is essential for intermale aggression. Our finding is a critical clue for unraveling how the BNST innately evaluates the biological meaning of new objects and regulates emotions.

The BNSTp has extensive connections with the MePD and hypothalamic periventricular region (Dong and Swanson, 2004; Choi et al, 2005), and it is notable that GABAergic neurons in the $\mathrm{MePD}$ have recently been reported to promote aggression, as well as two other innate social behaviors, mating and social grooming (Hong et al, 2014). Furthermore, the ventrolateral part of the ventromedial nucleus is reported to control male-to-male and male-tofemale social behaviors, such as aggressive behavior, mount, and sniffing (Lee et al, 2014). mGluR7 could have a critical role in some part of this pathway.

\section{Possible Mechanisms for How mGluR7 Regulates the Excitability of the BNST}

There are multiple possibilities for how mGluR7 regulates the excitability of groups of neurons. The reduced c-Fos-ir in the BNST of mGluR7 KO mice (Figure $4 \mathrm{e}$ and $\mathrm{f}$ ) provides important evidence for resolving the mechanism. It is quite likely that mGluR7-expressing axons are glutamatergic and assembled to innervate specific GABAergic interneurons in the BNST, because particular inhibitory neurons are decorated with many axon terminals intensely labeled for group III mGluRs in several brain areas (Shigemoto et al, 1996, 1997; Kinoshita et al, 1998). If so, mGluR7 works as an autoreceptor that inhibits glutamate release and maintains the appropriate inhibition mediated by decorated interneurons. In this case, mGluR7 deficiency would inhibit the excitation of BNST neurons that regulate the intermale aggression, via hyperactivation of decorated inhibitory interneurons. The unique expression of mGluR7-that is, target cell specificity and decoration pattern (Shigemoto et al, 1996; Kinoshita et al, 1998)_enables mGluR7 to regulate decorated interneurons strictly and to control the excitability of the local circuit strongly.

In case mGluR7 expressed in glutamatergic axon terminals connects to the excitatory neurons, it is plausible to assume a facilitatory effect of mGluR7. In addition to presynaptic inhibition, mGluR7 has recently been implicated in a novel form of metaplasticity in the hippocampus (Pelkey et al, 2005, 2008). These elegant studies showed that mGluR7 works as a gatekeeper for metaplasticity. In other words, mGluR7 can determine the direction of plasticity, long-term depression vs long-term potentiation. Because this process involves internalization of mGluR7, it has been thought that mGluR7 is merely inactivated, but our c-Fos data indicate another scenario: the synaptic transmission of mGluR7internalized presynapses must be different from those presynapses that genuinely lack mGluR7. Alteration of synaptic efficacy from depression to potentiation must have a particular impact on enhanced transmission, as supported by the fact that strong stimulation with mGluR7-specific agonists can increase glutamate release (Martín et al, 2010).

In addition to glutamatergic terminals, mGluR7 is also expressed at GABAergic terminals and modulates GABA release (Kinoshita et al, 1998; Somogyi et al, 2003; Summa et al, 2013), suggesting that mGluR7 at GABAergic terminals enhances neuronal excitation by modulating GABA release. In all those cases, mGluR7 must act as an 'enhancer of excitation'. Thus mGluR7 is certainly required for strong excitation of neurons in the BNST in order to process olfactory information, which is required for social recognition. As mGluR4 and mGluR8, which belong to group III mGluRs, are also known to show distinct localization similar to that of mGluR7 in several brain areas (Shigemoto et al, 1997), it is intriguing to speculate their cooperative or reciprocal interactions in regulating neural activities. 
Although the physiological relevance of their properties remains to be fully elucidated, here we demonstrate the pivotal role of mGluR7 as an enhancer of excitation in vivo and its significance in intermale aggression.

\section{FUTURE PERSPECTIVES AND CONCLUSIONS}

Like other subtypes of mGluRs, mGluR7 is anticipated to be involved in human disease (Nicoletti et al, 2011). mGluR7 KO mice show a deficit in social recognition, aggression, anxiety and fear, stress responses, motivation, aversion learning, and memory (Masugi et al, 1999; Sansig et al, 2001; Cryan et al, 2003; Callaerts-Vegh et al, 2006), and this phenotype suggest that mGluR7 is an essential component of social behavior and innate behavior. By investigating how mGluR7 regulates these emotional behaviors, our current findings could also pave the way toward future discoveries of novel therapies for emotional disorders in humans.

Although the heterogeneity and complexity of the BNST hampered identification of the profiles of mGluR7expressing neurons and their targets, our study shines a light on the function of the BNST by focusing on mGluR7. In the future, we should elucidate the constituents of the cytoarchitecture and physiological function of the BNST, and we will understand the mechanisms of emotional behaviors, such as aggression, social behavior, and fear. Quite surprisingly, the presynaptic molecule mGluR7 has such a large effect on the excitability of groups of BNST neurons. Further investigations of the role of mGluR7 in the BNST are likely to shed light on the novel principles of synaptic modulation within the neural circuits.

\section{FUNDING AND DISCLOSURE}

This work was supported by Grants-in-Aid for Scientific Research from the Ministry of Education, Culture, Sports, Science and Technology in Japan (KAKENHI 20240036 and 24300128 to MK, and KAKENHI 20500313 and 23500415 to MMT), and Grant FL 729/2-1 from the German Research Foundation (DFG) to PJF. The authors declare no conflict of interest.

\section{ACKNOWLEDGMENTS}

Our special thanks to Dr Herman van der Putten from the Novartis Institutes for BioMedical Research (Basel, Switzerland) for providing the mGluR7 KO mice and Dr Ryoichiro Kageyama for excellent research environment.

\section{REFERENCES}

Alheid GF, de Olmos JS, Beltramino CA (1995). Amygdala and extended amygdala. In: Paxinos G (ed). The Rat Nervous System. Academic Press: San Diego, CA, USA, pp 495-578.

Bienkowski MS, Wendel ES, Rinaman L (2013). Organization of multisynaptic circuits within and between the medial and the central extended amygdala. J Comp Neurol 521: 3406-3431.

Calcagnoli F, de Boer SF, Beiderbeck DI, Althaus M, Koolhaas JM, Neumann ID (2014). Local oxytocin expression and oxytocin receptor binding in the male rat brain is associated with aggressiveness. Behav Brain Res 261: 315-322.
Caldwell HK, Lee HJ, Macbeth AH, Young WS 3rd (2008). Vasopressin: behavioral roles of an 'original' neuropeptide. Prog Neurobiol 84: 1-24.

Callaerts-Vegh Z, Beckers T, Ball SM, Baeyens F, Callaerts PF, Cryan JF et al (2006). Concomitant deficits in working memory and fear extinction are functionally dissociated from reduced anxiety in metabotropic glutamate receptor 7 -deficient mice. J Neurosci 26: 6573-6582.

Carrillo M, Ricci LA, Melloni RH (2011). Glutamate-vasopressin interactions and the neurobiology of anabolic steroid-induced offensive aggression. Neuroscience 185: 85-96.

Chamero P, Marton TF, Logan DW, Flanagan K, Cruz JR, Saghatelian A et al (2007). Identification of protein pheromones that promote aggressive behaviour. Nature 450: 899-902.

Choi DC, Furay AR, Evanson NK, Ostrander MM, Ulrich-Lai YM, Herman JP (2007). Bed nucleus of the stria terminalis subregions differentially regulate hypothalamic-pituitary-adrenal axis activity: implications for the integration of limbic inputs. J Neurosci 27: 2025-2034.

Choi GB, Dong HW, Murphy AJ, Valenzuela DM, Yancopoulos GD, Swanson LW et al (2005). Lhx6 delineates a pathway mediating innate reproductive behaviors from the amygdala to the hypothalamus. Neuron 46: 647-660.

Conn PJ, Christopoulos A, Lindsley CW (2009). Allosteric modulators of GPCRs: a novel approach for the treatment of CNS disorders. Nat Rev Drug Discov 8: 41-54.

Cryan JF, Kelly PH, Neijt HC, Sansig G, Flor PJ, van Der Putten H (2003). Antidepressant and anxiolytic-like effects in mice lacking the group III metabotropic glutamate receptor mGluR7. Eur J Neurosci 17: 2409-2417.

D'Eath RB, Ormandy E, Lawrence AB, Sumner BE, Meddle SL (2005). Resident-intruder trait aggression is associated with differences in lysine vasopressin and serotonin receptor $1 \mathrm{~A}$ (5-HT1A) mRNA expression in the brain of pre-pubertal female domestic pigs (Sus scrofa). J Neuroendocrinol 17: 679-686.

De Vries GJ, Buijs RM (1983). The origin of the vasopressinergic and oxytocinergic innervation of the rat brain with special reference to the lateral septum. Brain Res 273: 307-317.

DeLeon KR, Grimes JM, Connor DF, Melloni RH Jr (2002). Adolescent cocaine exposure and offensive aggression: involvement of serotonin neural signaling and innervation in male Syrian hamsters. Behav Brain Res 133: 211-220.

Denenberg VH, Gaulin-Kremer E, Gandelman R, Zarrow MX (1973). The development of standard stimulus animals for mouse (Mus musculus) aggression testing by means of olfactory bulbectomy. Anim Behav 21: 590-598.

Dong HW, Swanson LW (2004). Projections from bed nuclei of the stria terminalis, posterior division: implications for cerebral hemisphere regulation of defensive and reproductive behaviors. J Comp Neurol 471: 396-433.

Fendt M, Schmid S, Thakker DR, Jacobson LH, Yamamoto R, Mitsukawa $\mathrm{K}$ et al (2008). mGluR7 facilitates extinction of aversive memories and controls amygdala plasticity. Mol Psychiatry 13: 970-979.

Ferris CF, Melloni RH Jr, Koppel G, Perry KW, Fuller RW, Delville $Y$ (1997). Vasopressin/serotonin interactions in the anterior hypothalamus control aggressive behavior in golden hamsters. J Neurosci 17: 4331-4340.

Franklin KBJ, Paxinos G (2007). The Mouse Brain in Stereotaxic Co-ordinates, 3rd edn. Academic Press: New York, NY, USA.

Hollmann M, Heinemann S (1994). Cloned glutamate receptors. Annu Rev Neurosci 17: 31-108.

Hong W, Kim DW, Anderson DJ (2014). Antagonistic control of social versus repetitive self-grooming behaviors by separable amygdala neuronal subsets. Cell 158: 1348-1361.

Hurst JL, Payne CE, Nevison CM, Marie AD, Humphries RE, Robertson DH et al (2001). Individual recognition in mice mediated by major urinary proteins. Nature 414: 631-634. 
Jennings JH, Rizzi G, Stamatakis AM, Ung RL, Stuber GD (2013a). The inhibitory circuit architecture of the lateral hypothalamus orchestrates feeding. Science 341: 1517-1521.

Jennings JH, Sparta DR, Stamatakis AM, Ung RL, Pleil KE, Kash TL et al (2013b). Distinct extended amygdala circuits for divergent motivational states. Nature 496: 224-228.

Ju G, Swanson LW (1989). Studies on the cellular architecture of the bed nuclei of the stria terminalis in the rat: I. Cytoarchitecture. J Comp Neurol 280: 587-602.

Kim SY, Adhikari A, Lee SY, Marshel JH, Kim CK, Mallory CS et al (2013). Diverging neural pathways assemble a behavioural state from separable features in anxiety. Nature 496: 219-223.

Kinoshita A, Shigemoto R, Ohishi H, van der Putten H, Mizuno N (1998). Immunohistochemical localization of metabotropic glutamate receptors, mGluR7a and mGluR7b, in the central nervous system of the adult rat and mouse: a light and electron microscopic study. J Comp Neurol 393: 332-352.

Kudo T, Uchigashima M, Miyazaki T, Konno K, Yamasaki M, Yanagawa $Y$ et al (2012). Three types of neurochemical projection from the bed nucleus of the stria terminalis to the ventral tegmental area in adult mice. J Neurosci 32: 18035-18046.

Lagerspetz KM, Lagerspetz KY (1971). Changes in the aggressiveness of mice resulting from selective breeding, learning and social isolation. Scand J Psychol 12: 241-248.

Lee H, Kim DW, Remedios R, Anthony TE, Chang A, Madisen L et al (2014). Scalable control of mounting and attack by Esr1+ neurons in the ventromedial hypothalamus. Nature 509: 627-632.

Leypold BG, Yu CR, Leinders-Zufall T, Kim MM, Zufall F, Axel R (2002). Altered sexual and social behaviors in trp2 mutant mice. Proc Natl Acad Sci USA 99: 6376-6381.

Mandiyan VS, Coats JK, Shah NM (2005). Deficits in sexual and aggressive behaviors in Cnga2 mutant mice. Nat Neurosci 8: 1660-1662.

Martín R, Durroux T, Ciruela F, Torres M, Pin JP, Sánchez-Prieto J (2010). The metabotropic glutamate receptor mGlu7 activates phospholipase $\mathrm{C}$, translocates munc-13-1 protein, and potentiates glutamate release at cerebrocortical nerve terminals. J Biol Chem 285: 17907-17917.

Masugi M, Yokoi M, Shigemoto R, Muguruma K, Watanabe Y, Sansig G et al (1999). Metabotropic glutamate receptor subtype 7 ablation causes deficit in fear response and conditioned taste aversion. J Neurosci 19: 955-963.

Miczek KA, Maxson SC, Fish EW, Faccidomo S (2001). Aggressive behavioral phenotypes in mice. Behav Brain Res 125: 167-181.

Mitsukawa K, Mombereau C, Lötscher E, Uzunov DP, van der Putten H, Flor PJ et al (2006). Metabotropic glutamate receptor subtype 7 ablation causes dysregulation of the HPA axis and increases hippocampal BDNF protein levels: implications for stress-related psychiatric disorders. Neuropsychopharmacology 31: $1112-1122$.

Moga MM, Saper CB, Gray TS (1989). Bed nucleus of the stria terminalis: cytoarchitecture, immunohistochemistry, and projection to the parabrachial nucleus in the rat. J Comp Neurol 283: 315-332.

Nakanishi S, Masu M (1994). Molecular diversity and functions of glutamate receptors. Annu Rev Biophys Biomol Struct 23: 319-348.

Nelson RJ, Trainor BC (2007). Neural mechanisms of aggression. Nat Rev Neurosci 8: 536-546.

Nicoletti F, Bockaert J, Collingridge GL, Conn PJ, Ferraguti F, Schoepp DD et al (2011). Metabotropic glutamate receptors: from the workbench to the bedside. Neuropharmacology $\mathbf{6 0}$ : 1017-1041.

Ogawa S, Robbins A, Kumar N, Pfaff DW, Sundaram K, Bardin CW (1996). Effects of testosterone and 7 alpha-methyl-19-nortestosterone (MENT) on sexual and aggressive behaviors in two inbred strains of male mice. Horm Behav 30: 74-84.

Ogawa S, Washburn TF, Taylor J, Lubahn DB, Korach KS, Pfaff DW (1998). Modifications of testosterone-dependent behaviors by estrogen receptor-alpha gene disruption in male mice. Endocrinology 139: 5058-5069.

Okamoto N, Hori S, Akazawa C, Hayashi Y, Shigemoto R, Mizuno $\mathrm{N}$ et al (1994). Molecular characterization of a new metabotropic glutamate receptor mGluR7 coupled to inhibitory cyclic AMP signal transduction. J Biol Chem 269: 1231-1236.

Patil SN, Brid SV (2010). Relative role of neural substrates in the aggressive behavior of rats. J Basic Clin Physiol Pharmacol 21: 357-367.

Pelkey KA, Lavezzari G, Racca C, Roche KW, McBain CJ (2005). mGluR7 is a metaplastic switch controlling bidirectional plasticity of feedforward inhibition. Neuron 46: 89-102.

Pelkey KA, Topolnik L, Yuan XQ, Lacaille JC, McBain CJ (2008). State-dependent cAMP sensitivity of presynaptic function underlies metaplasticity in a hippocampal feedforward inhibitory circuit. Neuron 60: 980-987.

Poulin JF, Arbour D, Laforest S, Drolet G (2009). Neuroanatomical characterization of endogenous opioids in the bed nucleus of the stria terminalis. Progr Neuropsychopharmacol Biol Psychiatry 33: $1356-1365$.

Sansig G, Bushell TJ, Clarke VR, Rozov A, Burnashev N, Portet C et al (2001). Increased seizure susceptibility in mice lacking metabotropic glutamate receptor 7. J Neurosci 21: 8734-8745.

Shaikh MB, Brutus M, Siegel HE, Siegel A (1986). Regulation of feline aggression by the bed nucleus of stria terminalis. Brain Res Bull 16: 179-182.

Shigemoto R, Kinoshita A, Wada E, Nomura S, Ohishi H, Takada M et al (1997). Differential presynaptic localization of metabotropic glutamate receptor subtypes in the rat hippocampus. J Neurosci 17: 7503-7522.

Shigemoto R, Kulik A, Roberts JD, Ohishi H, Nusser Z, Kaneko T et al (1996). Target-cell-specific concentration of a metabotropic glutamate receptor in the presynaptic active zone. Nature 381: 523-525.

Simerly RB (2002). Wired for reproduction: organization and development of sexually dimorphic circuits in the mammalian forebrain. Annu Rev Neurosci 25: 507-536.

Somogyi P, Dalezios Y, Luján R, Roberts JD, Watanabe M, Shigemoto $\mathrm{R}$ (2003). High level of mGluR7 in the presynaptic active zones of select populations of GABAergic terminals innervating interneurons in the rat hippocampus. Eur J Neurosci 17: 2503-2520.

Stowers L, Holy TE, Meister M, Dulac C, Koentges G (2002). Loss of sex discrimination and male-male aggression in mice deficient for TRP2. Science 295: 1493-1500.

Summa M, Di Prisco S, Grilli M, Usai C, Marchi M, Pittaluga A (2013). Presynaptic mGlu7 receptors control GABA release in mouse hippocampus. Neuropharmacology 66: 215-224.

Veenema AH, Neumann ID (2008). Central vasopressin and oxytocin release: regulation of complex social behaviours. Prog Brain Res 170: 261-276.

Yoon H, Enquist LW, Dulac C (2005). Olfactory inputs to hypothalamic neurons controlling reproduction and fertility. Cell 123: 669-682.

Supplementary Information accompanies the paper on the Neuropsychopharmacology website (http://www.nature.com/npp) 